\title{
Production of $\mathrm{Mg}-3 \mathrm{Al}$ Based Composites Reinforced with Ti6Al4V Particles
}

\begin{abstract}
L.C. Kumruoglu*
University of Cumhuriyet, Engineering Faculty, Metallurgy and Materials Department, Sivas, Turkey

Stir casting is one of the simple, flexible and the cost effective methods for fabricating of metal matrix composites reinforced with particles. In this study, 5\%, 10\%, 15 vol.\% Ti6Al4V particles were added into the $\mathrm{Mg}-3 \mathrm{Al}$ melt during stirring. The tensile strength of $\mathrm{Mg}-3 \mathrm{Al}$ alloy was between $150-190 \mathrm{MPa}$ and 5 vol.\% Ti6Al4V/ $\mathrm{Mg}-3 \mathrm{Al}$ alloy was equal. However, increasing the particle volume of Ti6Al4V powders to 10 vol. $\%$ and 15 vol.\% decreased the ultimate tensile strength of composites to 140-170 MPa and 90-110 MPa, respectively. On the other hand, the hardness of reinforced composite was increased for each volume.
\end{abstract}

DOI: $10.12693 /$ APhysPolA.125.432

PACS: 83.80.Ab, 81.05.Bx, 81.05.Ni, 81.70.-q

\section{Introduction}

Magnesium is the lightest of all the structural metallic materials and is primarily used in engineering alloys due to its low density, fatigue resistance, high strength-to-density ratio, machining ability and castability $[1,2]$. Pure magnesium is not appropriately robust to be used in many engineering applications. Magnesium matrix composites occupy various advantages over monolithic $\mathrm{Mg}$ alloys, for example high specific strength and stiffness, high elastic modulus, good creep, and wear resistances [3]. Furthermore, particle reinforced Mg composites produced by stir casting are very economic, capable of several applications in the aerospace, defense, and automobile industries [3]. However, the relatively low corrosion and wear resistance of magnesium alloys restricted their widespread use [4]. So as to develop the mechanical properties of $\mathrm{Mg}$ alloys, research efforts have been focused on the development of metal matrix composites. Mg can be reinforced with hard ceramic particles. Conversely, it may reduce the ductility and toughness. In comparison with ceramic particles, metallic particles mostly have a much better wettability with liquid metals [5], better ductility and mechanical compatibility through the metallic matrix can be potentially employed as a reinforcement component in metal matrix composites [6]. Considering the low density, high strength and more biocompatibility, the Ti and its alloys are the promising candidates for the reinforcement materials. Ti6Al4V alloy is not only lighter, but also has three times higher yield and tensile strength than pure Ti [5]. Finally, the nodular particles made from Ti6Al4V alloy have been added to the $\mathrm{Mg}-3 \mathrm{Al}$ alloy.

This article presents an attempt onto production of $\mathrm{Mg}-3 \mathrm{Al}$ (matrix)-Ti6Al4V (reinforcement) composite via stir casting route. The stir casting process was also

*e-mail: leventcenk@gmail.com verified and optimized by computer simulation. Eventually, the final microstructure and mechanical properties such as yield-ultimate tensile strength, elongation, and microhardness have been investigated.

\section{Experimental studies}

Conventional gravity casting is still the most widely used method of casting magnesium alloys. That is why gravity casting method was preferred to produce pre-alloy. The $\mathrm{Mg}-3 \mathrm{Al}(97 \% \mathrm{Mg}, 3 \% \mathrm{Al})$ alloy was melted in a graphite crucible with the induction heater protected by $\mathrm{CO}_{2}-2 \% \mathrm{SF}_{6}$. The volumes of $\mathrm{Ti} 6 \mathrm{Al} 4 \mathrm{~V}$ particles in ratio of $0 \%, 5 \%, 10 \%$ and 15 vol. $\%$ were prepared by vortex method injecting the particles into the $\mathrm{Mg}-3 \mathrm{Al}$ melt while the melt was stirred. A Microtrac Flex particle size analyzer characterized Ti6Al4V particles. The average size of $\mathrm{Ti} 6 \mathrm{Al} 4 \mathrm{~V}$ particles was $280 \mu \mathrm{m}$ (diameter) (Fig. 1) and the shape of particles was sphere. The stirring was continued for $15 \mathrm{~min}$ to produce homogeneous mixture. The speed of impeller was $250 \mathrm{rpm}$.

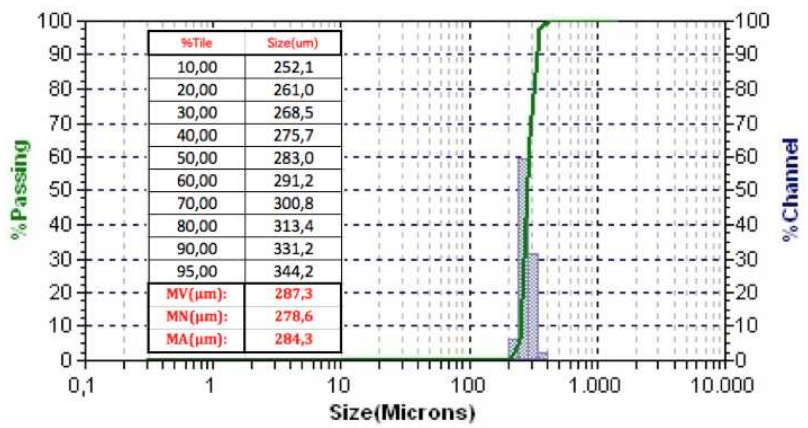

Fig. 1. Average diameter and ratio of Ti6AL4V particles.

The stirring continued to prepare the homogeneous slurry. After stirring, the composite slurry was poured into the graphite mold. The pouring temperature was selected as $750^{\circ} \mathrm{C}$. The temperature of composite slurry 
was measured by $\mathrm{K}$ type thermocouples that were placed in the bottom of mold during the pouring and solidification. The cast part of composite and the tensile test specimen (TTS) that were cut by wire erosion machine from the bottom side were shown in Fig. 2. TTSs were cut from the part via wire erosion (dashed lines) machine and thickness of the tensile test specimens was $4 \mathrm{~mm}$.

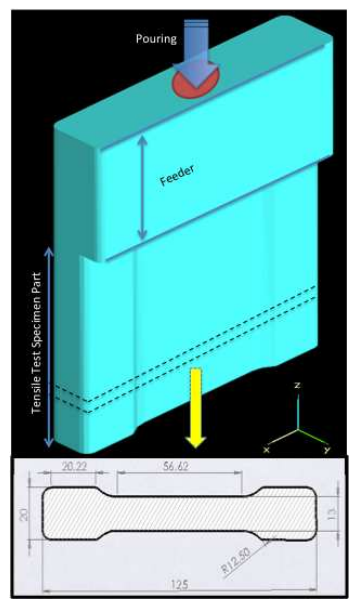

Fig. 2. The cast part of composite and the dimensions of specimen for tensile test.

Standard metallography was conducted to polish mirror finish and specimens were dried by hot air. Optical and scanning electron microscopy were used to examine the general structure and particulate distribution in the matrix and the composites. Also fractured surface of TTS, interface of particle and matrix, and wettability properties were investigated by both microscopy techniques. Microhardness and Brinell hardness measurements were performed. According to the measured temperatures from the thermocouples, flow rate and particle orientation in mold, the computer simulation software that simulates the temperature profile and particle movement was executed to predict the final location of particles.

\section{Result and discussions}

Simulation results and particle flow into the mold for (a) $5 \%$, (b) $10 \%$, (c) side view of picture (b), (d) temperature of composite part and graphite mold, (e) $15 \%$ Ti6Al4V particles located in the mold were shown in Fig. 3. The optical microscopy results were shown in Fig. 4.

Scanning electron microscope and energy dispersive spectrometer (SEM-EDS) images showing the grain morphology and elemental concentration at the grain boundaries and in the grain were shown in Fig. 5. As it can be seen from the EDS tables the Al concentration is higher at the grain boundaries $(1,4,5)$ than the grain $(2,3)$. Mainly, Ti and $\mathrm{V}$ was detected from the specimens. According to the EDS results, $\mathrm{Mg}$ and $\mathrm{Al}$ elements may form an intermetallic phase at the grain boundaries.

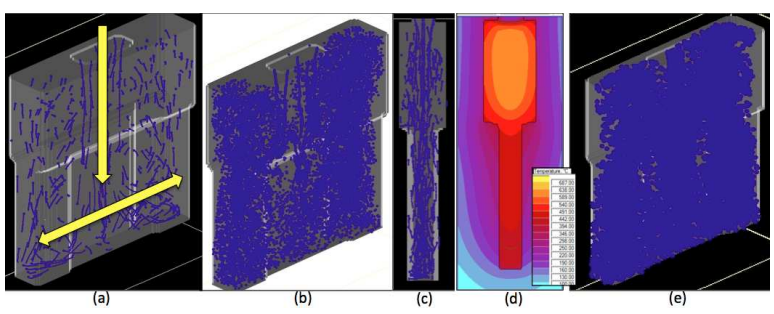

Fig. 3. Particle distribution of (a) 5\%, (b) 10\%, (c) side view of picture (b), (d) temperature of composite part and graphite mold, (e) $15 \% \mathrm{Ti} 6 \mathrm{Al} 4 \mathrm{~V}$ in the mold.

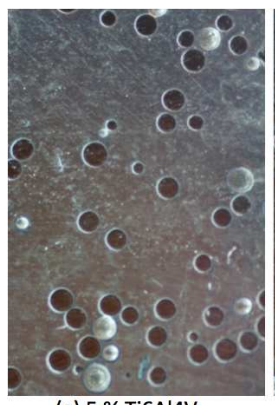

(a) $5 \%$ Ti6Al4V

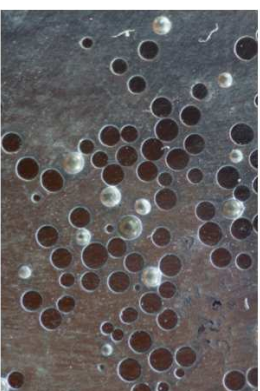

(b) $10 \%$ Ti6Al4V

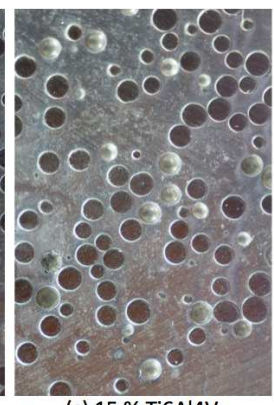

(c) $15 \%$ Ti6Al4V
Fig. 4. Particle distribution of (a) 5\%, (b) 10\%, (c) $15 \% \mathrm{Ti} 6 \mathrm{Al} 4 \mathrm{~V}$ taken from the polished surfaces of specimens.

Figure 6 shows the SEM photograph of fractured surface of $5 \%$ and $15 \% \mathrm{Ti} 6 \mathrm{Al} 4 \mathrm{~V}$ specimens. The Ti6Al4V particles and their interface between matrixes are shown in Fig. 6. SEM images show that the particles have good wettability in the matrix. EDS spectra also detected very thin $\mathrm{Mg}$ layers on the Ti6Al4V spheres. It means that the $\mathrm{Mg}-3 \mathrm{Al}$ metal covered the particles surface.

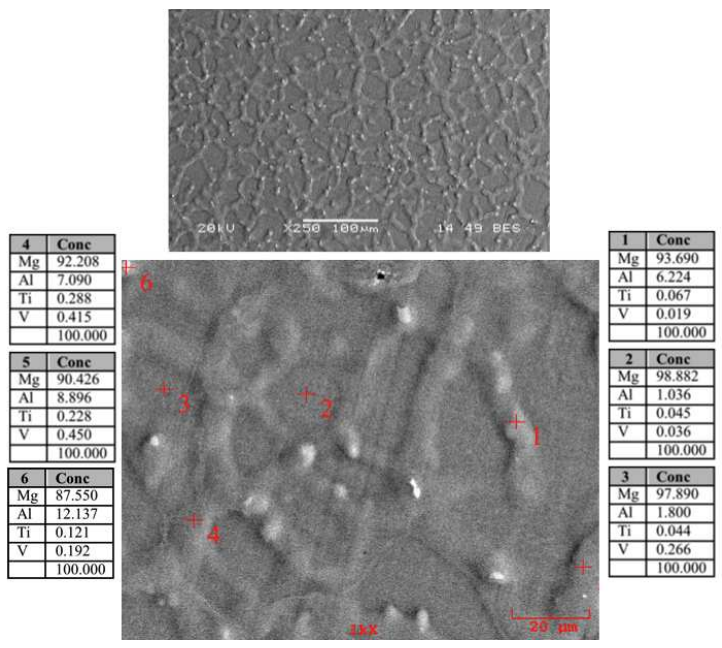

Fig. 5. SEM view of polished and etched surfaces of $5 \% \mathrm{Ti} 6 \mathrm{Al} 4 \mathrm{~V}$ injected matrix. 

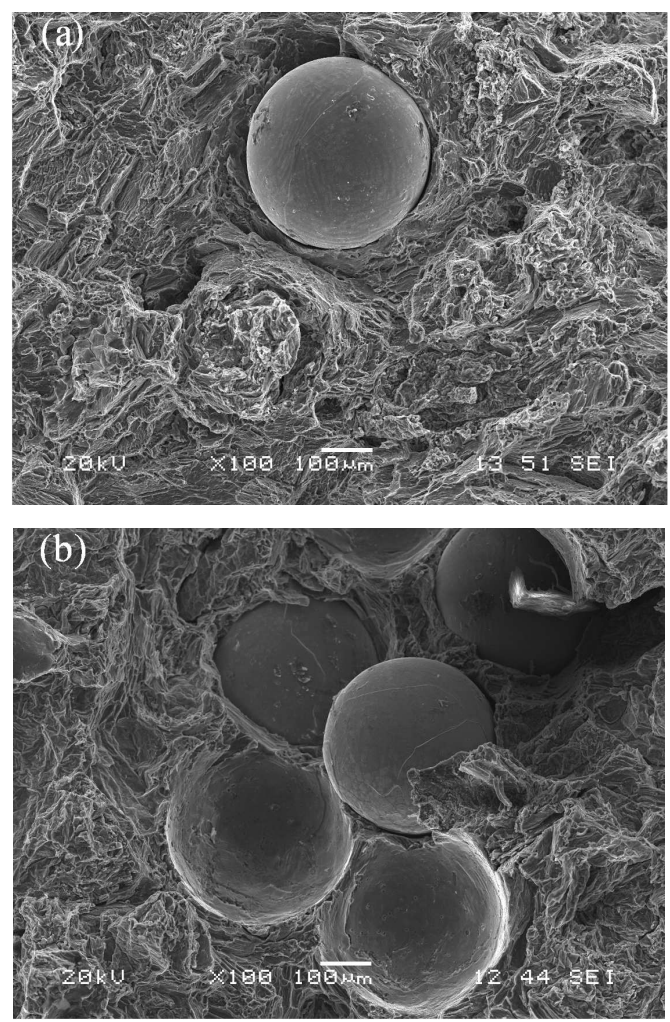

Fig. 6. SEM view of fractured surfaces of (a) $5 \%$ Ti6Al4V and (b) $15 \%$ Ti6Al4V specimens.

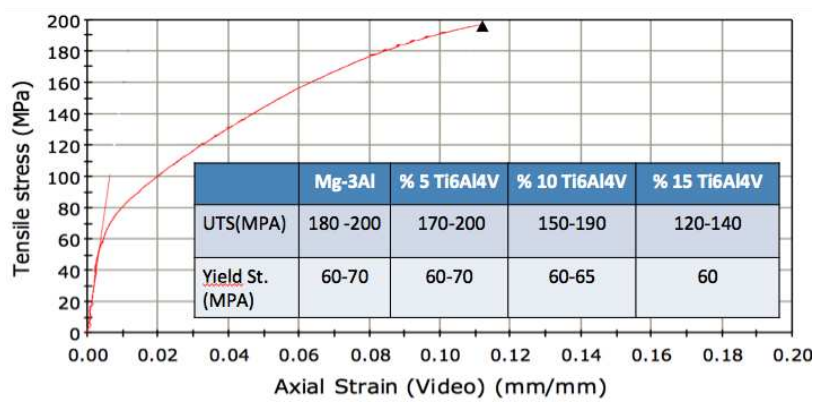

Fig. 7. Tensile test graph of $5 \%$ Ti6Al4V specimen and the table of tensile test reports of all specimens.
Tensile test results were given in Fig. 7. It can be concluded that tensile strength of $15 \%$ reinforced specimen is the lowest value, but $5 \%$ and $10 \%$ are closer to the $\mathrm{Mg}-3 \mathrm{Al}$ mechanical properties. On the other hand, the yield strength of composite is also closer to the $\mathrm{Mg}-3 \mathrm{Al}$. On the other hand, the hardest one was $15 \%$ Ti6Al4V specimen (90 HBN-hardness Brinell).

\section{Conclusions}

Ti6Al4V particle reinforced $\mathrm{Mg}-3 \mathrm{Al}$ alloy based metal matrix composites were successfully produced by using vortex method and gravity casting technique. The results obtained from the microstructure investigations reveal that the homogeneous particle distributions in the composites were obtained. The addition of Ti6Al4V particles increased the density of the composites and hardness. HBN increased linearly with increasing particles volume fraction. The highest values were obtained from the $15 \%$ Ti6Al4V-Mg-3Al composite. Tensile strength decreased with increasing the particle volume fraction.

\section{References}

[1] A.A. Luo, M.O. Pekguleryuz, J. Mater. Sci. 29, 5259 (1994).

[2] K.U. Kainer, Magnesium Alloys and Technology, Wiley-VCH, Weinheim 2003.

[3] X.J. Wang, X. Hu, K. Wu, M Zheng, Q. Zhai, J. Mater. Sci. 44, 2759 (2009).

[4] X.J. Li, X.Y. Liu, B.L. Luan, Appl. Surf. Sci. 257, 9135 (2011).

[5] H.Z. Ye, X.Y. Liu, J. Alloys Comp. 402, 162 (2005).

[6] C.K. Seal, K. Vince, M.A. Hodgson, Mater. Sci. Eng. A 4, 012011 (2009). 